\title{
(1)
}

UNIVERSIDAD PERUANA DE CIENCIAS APLICADAS

FACULTAD DE NEGOCIOS

PROGRAMA ACADÉMICO DE NEGOCIOS INTERNACIONALES

\section{Desarrollo de ventajas competitivas desde el enfoque de la gestión de residuos sólidos orgánicos en las agroexportadoras de café en la región San Martin}

\section{TESIS}

para optar el título profesional de: Licenciado en Negocios Internacionales

\section{AUTORES}

Chira Jacinto, Julio Diego Alejandro (0000-0001-8345-5024)

Pino Silva, Alessandro Diego (0000-0001-7614-4121)

ASESOR

Esparta Sánchez, Miguel Angel (0000-0001-8345-5024) 


\section{TABLA DE CONTENIDO}

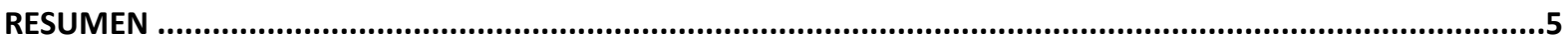

ABSTRACT

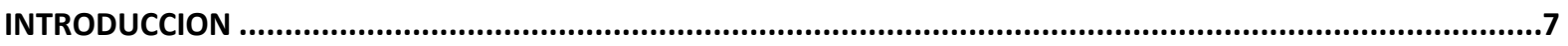

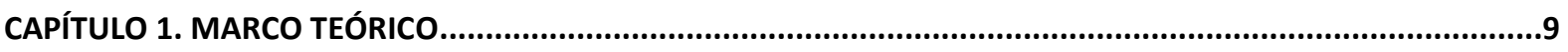

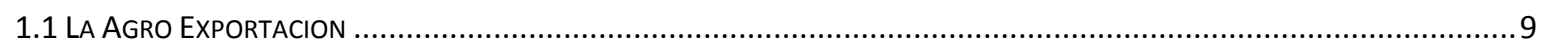

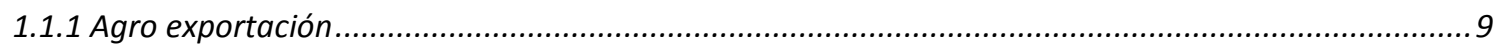

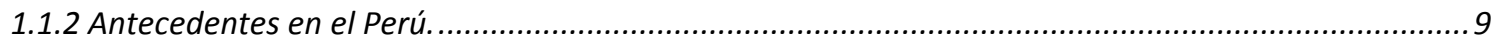

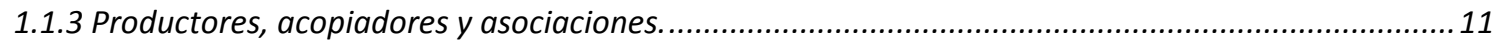

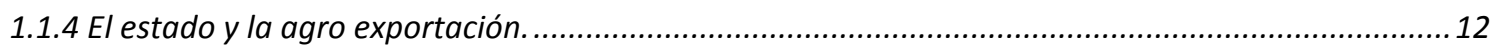

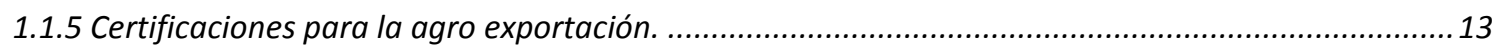

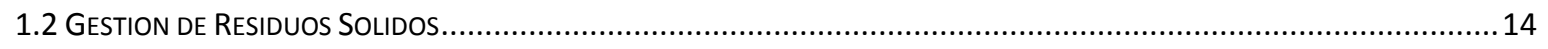

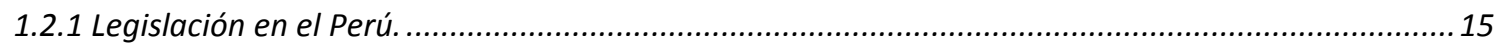

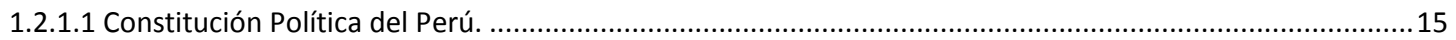

1.2.1.2 Código del Medio Ambiente y los Recursos Naturales............................................................................15

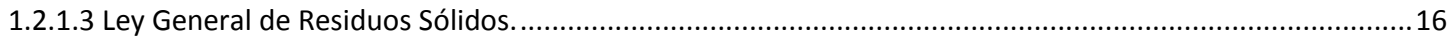

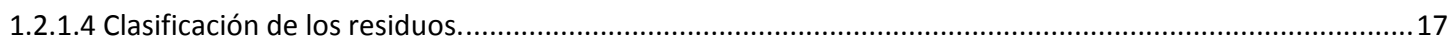

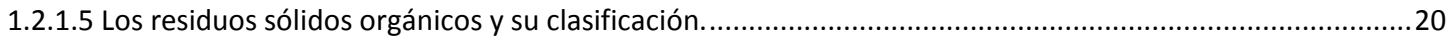

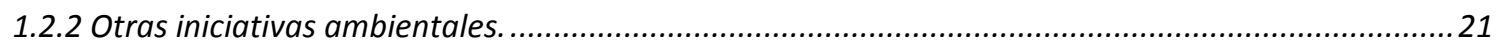

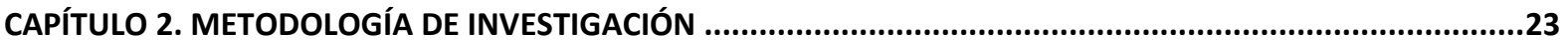

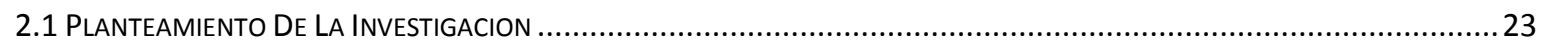

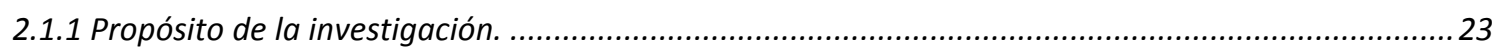

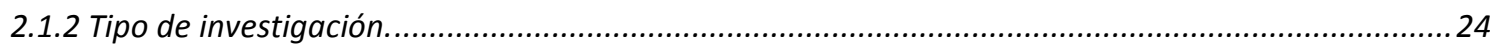

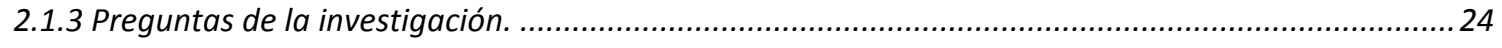

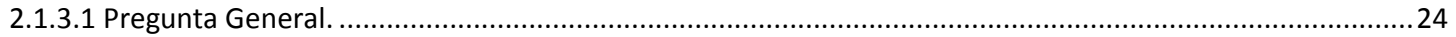

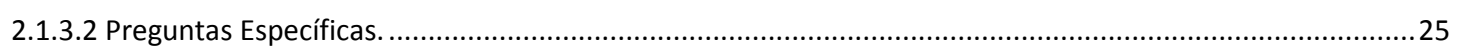

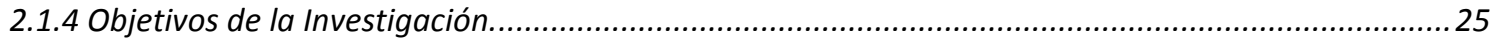

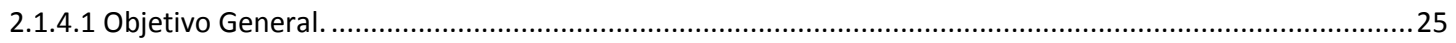

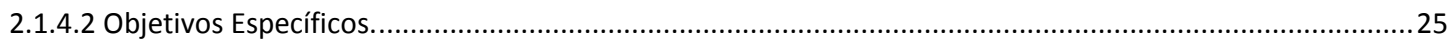

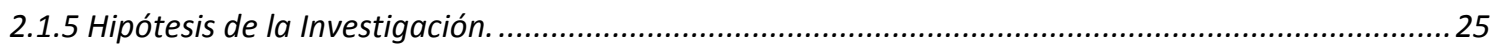

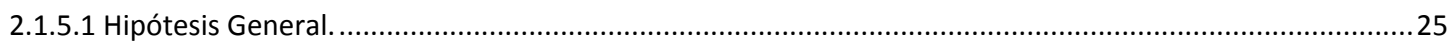

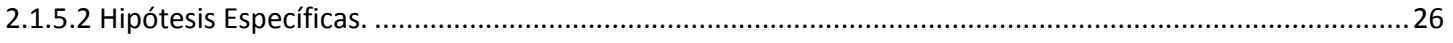

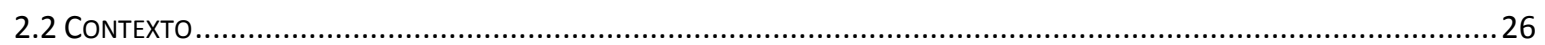

2.3 MUESTRA O PARTICIPANTES. 


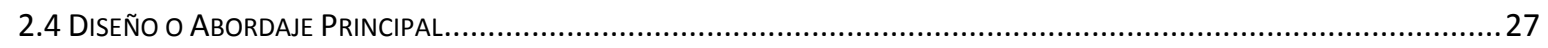

2.4.1 Identificación de la estructura de la entrevista.........................................................................2 27

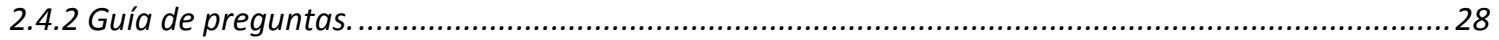

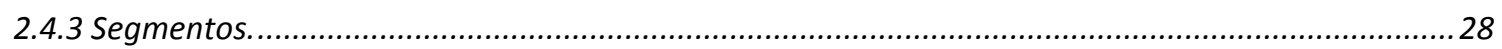

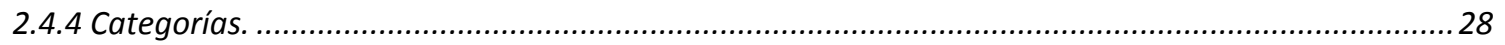

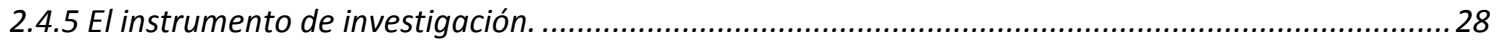

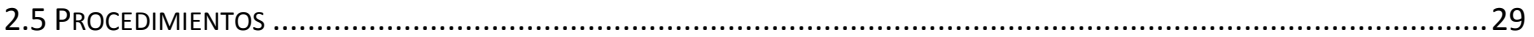

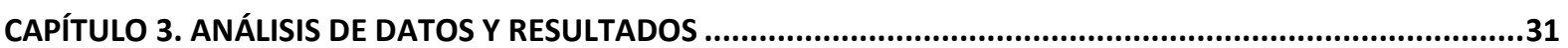

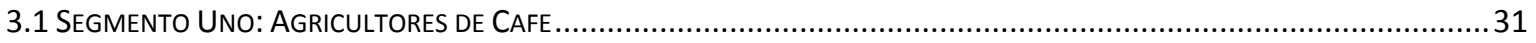

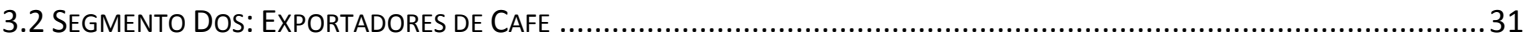

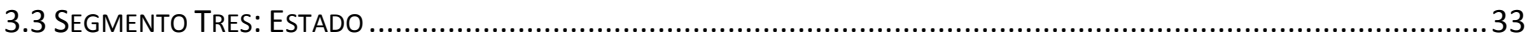

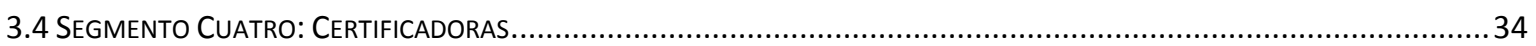

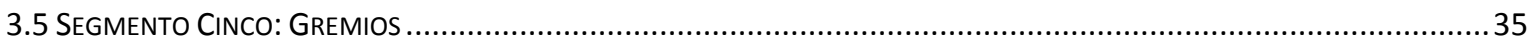

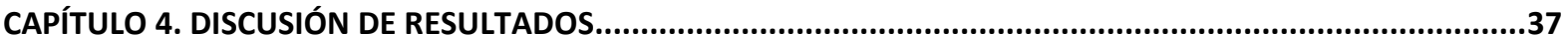

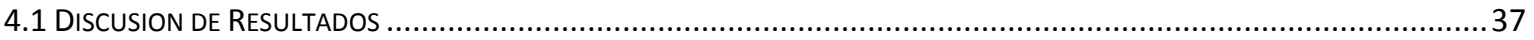

4.1.1 Discusión de resultados de Categoría 1: Impacto medioambiental. ............................................37

4.1.2 Discusión de resultados de Categoría 2: Método de Valorización de Residuos. .................................38

4.1.3 Discusión de resultados de Categoría 3: Oportunidades de Desarrollo Económico ...........................38

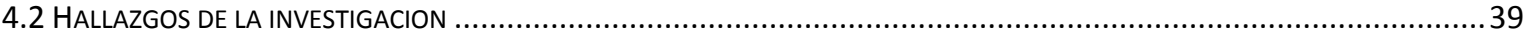

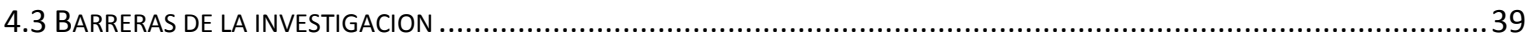

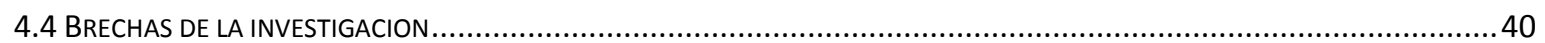

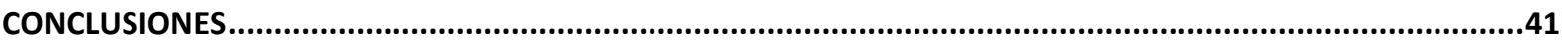

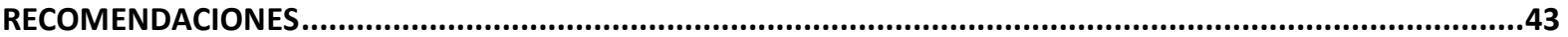

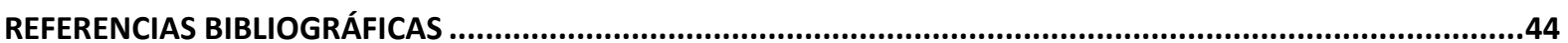

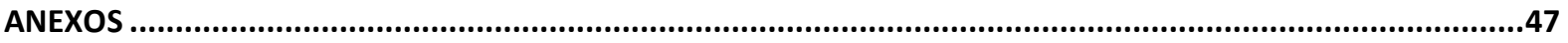




\section{ÍNDICE DE FIGURAS}

FIGURA 1: EXPORTACIONES AGROPECUARIAS- VALOR FOB (MILLONES USD) ..............................................47

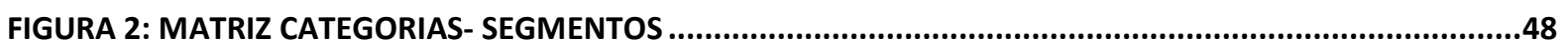




\section{RESUMEN}

La siguiente investigación se enfoca en el análisis del concepto de gestión de residuos sólidos orgánicos, como generadora de ventajas competitivas, implementada en las actividades agroexportadoras de café.

La gestión de residuos sólidos aparece como respuesta al interés de generar el menor riesgo para la salud y medio ambiente, permitiendo visualizar un nuevo concepto de negocio que puede ser aprovechado por las agroexportadoras. Esta gestión nos lleva a incorporar una serie de reglas y actividades en forma voluntaria, que permite generar compromiso con el medio ambiente y el entorno, desarrollando un nuevo paradigma que junto a las actividades agroexportadoras nos permite obtener fuentes de ventajas competitivas.

Para explicar la ventaja que se desarrolla la implementar la gestión de residuos sólidos orgánicos investigaremos el impacto medio ambiental, los métodos de valorización de residuos y las oportunidades de desarrollo económico.

Palabras clave : residuos sólidos ; agroexportadoras ; café ; gestión de residuos orgánicos 
This research focuses on the analysis of the management concept of organic solids, as a generator of competitive advantages, implemented in the agro-export activities of coffee.

The solid waste management appears in response to the interest of generating the lowest risk to health and the environment, you can visualize a new business concept that can be exploited by agro-exporters. This management leads us to incorporate a series of rules and activities on a voluntary basis, which allows us to generate commitment to the environment and the environment, develop a new paradigm that, together with agro-export activities, allows us to obtain sources of competitive advantages.

To the explain the advantage that it can implement the management of organic waste, environmental impact research, recovery methods and opportunities for economic development.

Keywords: Solid waste; agro-exporters; coffee; organic waste management 


\section{INTRODUCCIÓN}

La información contenida en esta investigación busca determinar cuál fue el desarrollo de ventajas competitivas desde el enfoque de la gestión integral de residuos sólidos orgánicos en las agroexportadoras de café en la región San Martin

En el primer capítulo se explica de forma detalla los aspectos relacionados con la agro exportación, los antecedentes en el Perú, los productores, acopiadores y asociaciones, el estado $\mathrm{y}$ las certificaciones.

Luego se explica sobre la gestión de residuos sólidos, la legislación en el Perú, la constitución política, el código del medio ambiente y los recursos naturales, la ley general de residuos sólidos, y la clasificación de los residuos sólidos.

Después de describir los conceptos relacionados con la investigación, en el segundo capítulo se muestra el planteamiento propuesto para la presente investigación, la cual a través de forma ordenada se aplicó para resolver la hipótesis inicial, además, se definen el planteamiento de investigación, el tipo de investigación y las preguntas de investigación, adicionalmente se mencionan las preguntas, objetivos e hipótesis, generales y específicas.

Además, se contó en las entrevistas con participación de los siguientes actores tales como: ECOM PERU, Picky Foods SA, APROECO, SUNAT, Avanza Sostenible SAC, Control Unión Perú SAC y Adex - Asociación de Exportadores.

Por otra parte, en el tercer capítulo se analiza los resultados obtenidos en la investigación de campo, también buscamos información actualizada que ayude entender el problema planteado y procesamos todos los datos recolectados con la finalidad de generar resultados que sirvan para el estudio.

Finalizando, el capítulo cuatro muestra el desarrolló, el cual se basa en los objetivos propuestos y los resultados obtenidos en cada categoría de preguntas, donde se discutirá los puntos más relevantes y se cruzara con información obtenida fundamentada en el marco teórico y análisis de campo, además se evaluará las implicancias de la investigación para determinar si se 
lograron alcanzaron los objetivos de la investigación, limitaciones, barreras y brechas, además se propondrá las conclusiones y recomendaciones del tema. 


\section{CAPÍTULO 1. MARCO TEÓRICO}

\subsection{La Agro Exportación}

\subsubsection{Agro exportación}

Según el diccionario de la Real Academia española ${ }^{12}$, Agro- significa campo y es utilizado como prefijo técnico para relacionar el campo con el comercio internacional, a su vez la palabra exportación significa acción de llevar productos fuera del país. Ambos conceptos nos lleva a concluir que la agro exportación es la labor de producir materia prima derivado de los productos agrícolas en determinada zonas o campos que luego serán consolidados para su comercialización con otros países.

La agro exportación conglomera todos aquellos productos de origen agrícolas, tal es el caso de los espárragos, arándanos, cacao, entre otras.

Por su lado, el modelo agroexportador es el nombre que recibe el modelo económico que se instala en un determinado país y que privilegia la producción agropecuaria de sus regiones por sobre la industrial, exportando por tanto comodities e importando productos manufacturados.

\subsubsection{Antecedentes en el Perú.}

Hacia finales del siglo XVIII las exportaciones principalmente eran de metales, aunque existe reportes de envío de cacao a la metrópoli ${ }^{3}$ (Banco Central de Reserva del Perú, 2010, pág. 414). En las primeras décadas del siglo XIX se empezó a exportar otros productos como la chancaca,

1 Real Academia Española (RAE). (2001). En Diccionario de la lengua española. $22^{a}$ ed. Recuperado de http://dle.rae.es/?id=1AVkVOV|1Aa47RA [Consulta: 05 de Abril de 2018]

2 Real Academia Española (RAE). (2001). En Diccionario de la lengua española. $22^{a}$ ed. Recuperado de http://dle.rae.es/?id=HKZN9p1 [Consulta: 05 de Abril de 2018]

${ }^{3}$ Anexo estadístico del Compendio de historia económica del Perú. Tomo 3. Economía del periodo colonial tardio. Lima: IEP/BCR, 2010, p. 414. Recuperado de http://www.bcrp.gob.pe/docs/Publicaciones/libros/historia/3-economia-colonialtardio.pdf [Consulta: 05 de Abril de 2018] 
las cuales se producían en las haciendas azucareras de la costa central. Posterior a la independencia las exportaciones agrarias obtuvieron mayor importancia, adicionalmente al cacao se empezó a exportar café, algodón, azúcar, lana de oveja, y fibra de alpaca. Después de la guerra con Chile los productos que sirvieron de impulso a la agricultura fueron la caña de azúcar y el algodón, así como la creación de los latifundios que aportaron en la innovación de la actividad agrónoma.

En 1930, el valor de las exportaciones de azúcar, algodón y lanas, eran similares a las exportaciones de minerales, los cuales en los siguientes años fueron superados largamente ${ }^{4}$ (Manrique, 2014, pág. 161). A finales de la década de 1950 y comienzos de la década de 1960 la fibra de algodón, azúcar y derivados alcanzaron sus mayores niveles de exportación lo cual contribuyo a la expansión de zonas agrícolas en la costa y a la ampliación de áreas de producción para el algodón y la caña ${ }^{5}$.

Entre 1969 y 1970, la agro exportación se redujo debido a las políticas aplicadas por la reforma agraria donde incluyeron la expropiación de las plantaciones cañeras y algodoneras. El algodón se volvió un producto de poca importancia y gran parte de la producción fue absorbida por la industria textil ${ }^{6}$ (Eguren, Fernández, \& Tume, 1981, pág. 122). Sin embargo otros productos como la producción del café cultivado principalmente en la selva tuvieron un incremento constante desde inicios de los años 1970.

Para la década de 1990, se inicia un nuevo periodo para la agro exportación, más amplio y diversificado. Entre 1994 y 2014, el valor total delas exportaciones agrícolas pasó de USD 476 millones a USD 5079 millones, siendo el principal producto de exportación agraria el café, seguido por los espárragos, quinua y la tara.

\footnotetext{
${ }^{4}$ Nelson Manrique. «Historia de la agro- cultura peruana», en Compendio de historia económica del Perú. Tomo 5. La economía peruana entre la Gran Depre- Sion y el reformismo militar 1930-1980. Lima: IEP/BCR, 2014, p. 161. Recuperado de http://www.bcrp.gob.pe/docs/Publicaciones/libros/historia/5-gran-depresion-y-reformismo-militar.pdf [Consulta: 05 de Abril de 2018]

${ }^{5}$ Rosemary Thor y Geoffrey Bertrán (1985). Crecimiento y políticas en una economía abierta. (pp. 351). Lima: Mosca Azul / Fundación Friedrich Ebert / UP

${ }^{6}$ Jorge Fernández Baca-Fabián Tune (1981). Producción algodonera e industria textil en el Perú. (pp.122). Lima: Desco
} 
En este crecimiento de la exportación cumplen un papel fundamental las agro exportadoras, que con nuevas técnicas de gestión y actualizaciones tecnológicas han aprovechado el boom exportador, además la concentración de propiedades de tierra para la producción contribuye a la creación de nuevos y modernos latifundios.

El estado ha cumplido un rol importante en los últimas décadas con la finalidad de contar con favorables condiciones legales, una de esas constituciones es del año 1993, ley 2605, de tierras donde busca dotar del máximo de seguridades a los propietarios agrícolas, regulando una forma muy particular de abandono de tierras, restringiendo las posibilidades de expropiación y estableciendo la servidumbre minera en caso de inicio de actividades de exploración y explotación.

\subsubsection{Productores, acopiadores y asociaciones.}

El Perú es uno de los principales productores de café en el mundo, su aroma y sabor son tan demandados que E1 95 \% de la producción de café de origen peruano se dirige a los mercados internacionales. Sus principales destinos son los mercados de Alemania, Estados Unidos, Canadá, Bélgica, Suecia, China y Corea $^{7}$. El Perú produce café de la variedad arábica, que es la mejor del mundo. Además, es el principal productor de café orgánico. Los cultivos más importantes provienen de Huánuco, Junín, Cajamarca, San Martín, Cusco, Amazonas, Pasco y Puno.

El café se produce en 210 distritos rurales ubicados en 47 provincias de 10 departamentos del total de veinticuatro que conforman el Perú. La superficie cultivada con café ocupa 230,000 hectáreas distribuidas en tres zonas, siendo la región más apropiada para obtener los mejores rendimientos con alta calidad la que se ubica al extremo central oriental de la Cordillera de los Andes, en la denominada zona de la selva, bajo una ecología tropical ${ }^{8}$.

\footnotetext{
7 Gestión - Grupo El Comercio (2011). Recuperado de https://archivo.gestion.pe/noticia/1316823/exportaciones-cafellegarian-us-1100-millones-este-ano?ref=gesr [Consulta: 05 de Abril de 2018$]$

8 Producción de Café Orgánico. Recuperado de http://cafe-peruano.com/produccion-de-cafe-organico-peru.php [Consulta: 05 de Abril de 2018]
} 
La zona norte consta de 98 mil hectáreas cafetaleras que constituyen el 43\% del área total cultivada y está conformada por los departamentos de Piura, Amazonas, Cajamarca y San Martín. La zona central abarca unas 79 mil hectáreas, es decir un 34\% de los cafetales de la nación, que comprende Junín, Huánuco y Pasco. En la zona sur, 53 mil hectáreas que componen el 23\% del hectárea total, está integrada por los departamentos de Apurímac, Ayacucho, Cusco y Puno.

En el Perú el café orgánico producido se cultiva sin el uso de agentes agroquímicos, para mantener la salud del consumidor, esto con la finalidad de no modificar la calidad del grano del café y fomentar la conservación del medio ambiente. Este manejo ecológico estimula el consumo por ser un producto natural, siendo una característica importante al existir una creciente demanda por consumir productos sin ningún tipo de alteración en su cultivo. Otro característica importante a considerar es la época de cultivo que es distinta a las de sus principales competidores como México y otros países de América Latina, en donde dicha característica resulta ser una ventaja al tener la posibilidad de cubrir la demanda del consumo del café orgánico, mientras otros países productores se encuentren en su etapa inicial de cultivo. Sin duda un punto a favor que beneficia al posicionar nuestro café en el mercado mundial. Asimismo, nuestro café está siendo reconocido a nivel mundial por medio de premios y reconocimientos internacionales, en donde se valora la calidad y aroma del café peruano que en los últimos años ha ganado mayores adeptos en su consumo al ser un producto con un alto valor agregado.

\subsubsection{El estado y la agro exportación.}

La economía del país ha estado vinculada a la agro exportación durante una parte importante de su historia. Hacia fines del siglo XVIII ${ }^{9}$, las exportaciones principales eran de metales. En las primeras décadas del siglo XIX se exportaba chancaca producida en las haciendas azucareras de la costa central a Chile. Luego de la independencia, las exportaciones agrarias

\footnotetext{
9 La Agro exportación en el Perú (2015). Recuperado de http://www.larevistaagraria.info/sites/default/files//revista/LRA173/LRA173 Agroexportacion MesaRedonda.pdf
}

[Consulta: 05 de Abril de 2018] 
adquirieron más importancia: al cacao se agregaron el café, la cinchona (para la extracción de quinina), el algodón, el azúcar, la fibra de alpaca y la lana de oveja. Después de la guerra con Chile, la producción de caña de azúcar y de algodón fue el motor de la modernización de la agricultura costeña y, también, de la formación de latifundios. En 1930, el valor de las exportaciones de algodón, azúcar y lanas era similar al de las que procedían de las mineras, y en los años siguientes las superaron largamente.

\subsubsection{Certificaciones para la agro exportación.}

En el Perú, el desarrollo de cultivos orgánicos es una tradición ancestral basada en una Gran diversidad de especies de plantas y animales, y los últimos 12 años el área sembrada de estos cultivos se ha multiplicado 6 veces, al pasar de 44 mil ha en 1995 a aproximadamente 300 mil ha en 2007.

La importancia de nuestro país en el panorama mundial es cada vez mayor, lo que puede apreciarse por los cerca de 35,000 productores orgánicos certificados, lo que nos coloca en el séptimo lugar en número de productores, después de México, Italia, Uganda, Tanzania, Filipinas y Sri Lanka.

Para el primer semestre del 2,008 se registraron 45,000 productores orgánicos Alrededor del 95\% de la producción orgánica nacional se exporta, y el resto se destina al mercado nacional, principalmente para su venta en supermercados.

Para exportar alimentos (productos agrícolas y agroindustriales) a la Unión Europea es necesario que la autoridad nacional se encuentre reconocida por la autoridad europea. Para el caso peruano, las autoridades sanitarias se encuentran reconocidas (SENASA y DIGESA) ${ }^{10}$. Posteriormente, una de estas entidades es la encargada de emitir los certificados sanitarios necesarios para la entrada de los productos al mercado europeo. Por otra parte, los establecimientos productores de alimentos registrados por la autoridad competente (en este

${ }^{10}$ Ministerio de Comercio Exterior y Turismo (MINCETUR). (2017). Guía de Requisitos Sanitarios y Fitosanitarios para la Agro Exportación la $\quad$ a $\quad$ Unión $\quad$ Europea. Recuperado de https://www.mincetur.gob.pe/wpcontent/uploads/documentos/comercio exterior/medidas Sanitarias Fitosanitarias/Guia U E_Alta.pdf [Consulta: 15 de abril de 2018] 
caso, SENASA y DIGESA) no requieren estar incluidos en una lista europea de establecimientos aprobados. Solo se requiere que sean reconocidos y registrados por la autoridad del tercer país (país europeo importador), que sean aceptados por los importadores de alimentos de la UE, y que cumplan con las siguientes exigencias:

a) Cumplimiento de las normas de higiene alimentaria

b) Cumplimiento del control microbiológico

\subsection{Gestión de Residuos Sólidos}

La generación de residuos sólidos del ámbito municipal durante el 2013, considerando exclusivamente el ámbito urbano del país llegó a 18,533t/día, de ello la recolección y transporte convencional con fines de disposición final alcanzó en promedio el $87.5 \%$ (16,216 t/día). De estos, sólo 7,656 t/día de residuos fueron dispuestos en un relleno sanitario autorizado considerándose un total de 10 infraestructuras de este tipo alrededor del país, mientras que 8,545 t/día terminaron en botaderos municipales y 300.3 t/día en otros destinos no especificados.

Por otro lado, hoy en día el avance de la tecnología y la mejora de la capacidad adquisitiva de la población viene permitiendo un aumento importante de la generación de residuos que devienen del uso cada vez mayor de los aparatos eléctricos y electrónicos en el país, constituyéndose en un serio problema sanitario y ambiental debido al manejo inadecuado del cual son objeto, debido a que los sistemas convencionales de manejo de residuos municipales no recogen este tipo de residuos y los mismos son captados por recicladores informales que los manipulan sin considerar los elementos y sustancias peligrosas que contienen en sus partes y componentes (metales pesados, sustancias químicas, etc.). 


\subsubsection{Legislación en el Perú.}

\subsubsection{Constitución Política del Perú.}

En la constitución política del Perú de 1993 en su capítulo II: Del Ambiente y los Recursos Naturales, Artículo $66^{\circ 11}$, indica que los recursos naturales, renovables y no renovables, son patrimonio de la Nación. El Estado es soberano en su aprovechamiento. Por ley orgánica se fijan las condiciones de su utilización y de su otorgamiento a particulares. La concesión otorga a su titular un derecho real, sujeto a dicha norma legal.

\subsubsection{Código del Medio Ambiente y los Recursos Naturales.}

El Código del Medio Ambiente y los Recursos Naturales (Decreto Legislativo No 613 del 08 de septiembre de 1990) señala en el Artículo I del Título Preliminar, que "Toda persona tiene derecho irrenunciable a gozar de un ambiente saludable, ecológicamente equilibrado y adecuado para el desarrollo de la vida, así como el deber de conservar dicho ambiente, además, precisa que es obligación del Estado mantener la calidad de vida de las personas a un nivel compatible con la dignidad humana".

En este contexto podemos tomar como referencia el consumo del agua, recurso natural primordial para la conservación de la vida humana, y no disponible a toda la población a nivel mundial.

En 1950, se estimaba que la población mundial era de 2.600 millones. Se alcanzaron los 5.000 millones en 1987 y, en 1999, los 6.000 millones. En octubre de 2011, se estimaba que la población mundial era de 7.000 millones. Por último, a mediados de 2015, la población mundial alcanzó los 7.300 millones de personas, lo que significa que en 12 años, el número de personas en el mundo ha aumentado en 1.000 millones $^{12}$ (Naciones Unidas, 2017). Estas cifras

11 Constitución Politica del Perú [Const.] (1993). http://pdba.georgetown.edu/Parties/Peru/Leyes/constitucion.pdf Recuperado de [Consulta: 13 de mayo de 2018]

12 Naciones Unidas. Población en Crecimiento http://www.un.org/es/sections/issues-depth/population/index.html Recuperado de [Consulta: 13 de mayo de 2018] 
nos muestra el incremento de la demanda en cuanto a suministros de agua potable para el consumo global.

En el Perú, la principal fuente, tanto para consumo humano o comercial, son los glaciares. El frio y las alturas de nuestras montañas permiten capturar el agua en estado gaseoso, lo convierte en hielo y luego lo hace fluir al subsuelo para dar vida a los riachuelos, sin embargo, este ciclo no es suficiente para cubrir la demanda total y más aún en esta etapa de calentamiento global que genera que los glaciares desaparezcan.

Frente al incremento de la agro exportación y al uso del agua que esta actividad demanda, se debe de implementar mejoras en la regulación del uso de recursos naturales para garantizar su sostenibilidad.

\subsubsection{Ley General de Residuos Sólidos.}

La Ley $27314^{13}$, Ley General de Residuos Sólidos, establece derechos, obligaciones, atribuciones y responsabilidades de la sociedad en su conjunto, para asegurar una gestión y manejo de los residuos sólidos, sanitaria y ambientalmente adecuada, con sujeción a los principios de minimización, prevención de riesgos ambientales y protección de la salud y el bienestar de la persona humana. En su artículo 14 del Título III "Manejo de Residuos Sólidos", establece, que son residuos sólidos aquellas sustancias, productos o subproductos en estado sólido o semisólido de los que su generador dispone, o está obligado a disponer, en virtud de lo establecido en la normatividad nacional o de los riesgos que causan a la salud y el ambiente, para ser manejados a través de un sistema que incluya, según corresponda, las siguientes operaciones o procesos:

\footnotetext{
${ }^{13}$ Ministerio del Ambiente. Ley General de Residuos Sólidos http://sinia.minam.gob.pe/normas/ley-general-residuos-solidos
} Recuperado de [Consulta: 13 de mayo de 2018] 

a) Minimizar residuos
b) Segregación en la fuente
c) Reaprovechamiento
d) Almacenamiento
e) Recolección
f) Comercialización
g) Transporte
h) Tratamiento
i) Transferencia
j) Disposición final

\subsubsection{Clasificación de los residuos.}

Los residuos se clasificas por estado, origen o por el tipo de manejo que se les da ${ }^{14}$.

\section{Clasificación por estado.}

Los residuos son definidos por su estado, según el estado físico en que se encuentre. Existe por lo tanto tres tipos de residuos desde este punto de vista: sólidos, líquidos y gaseosos. Es importante anotar que el alcance real de esta clasificación puede fijarse en términos meramente descriptivos o, como es realizado en la práctica, según la forma de manejo asociado.

14 Alaba, L. (2013). Gestión de Aprovechamiento de los Residuos Sólidos en la Región Cajamarca. (Monográfico de Licenciatura, Faculta de Ciencias Agrarias, Universidad Nacional de Cajamarca. Cajamarca, Perú) 


\section{Clasificación por origen.}

Se puede definir el residuo por la actividad que lo origine, esencialmente es una clasificación sectorial.

Según esta clasificación, los tipos de residuos más importantes son:

Residuos sólidos urbanos.

Los que componen la basura doméstica; la generación de residuos varía en función de factores culturales asociados a los niveles de ingreso, hábitos de consumo, desarrollo tecnológico y estándares de calidad de vida de la población.

Residuos industriales.

La cantidad de residuos que genera una industria durante el proceso productivo, la calidad de las materias primas o productos intermedios, propiedades físicas y químicas de las materias auxiliares empleadas, los envases y embalajes del proceso. Entre los residuos que genera la industria es importante diferenciar entre: Inertes: son los escombros y materiales similares. Es un residuo estable en el tiempo, el cual no producirá efectos ambientales apreciables al interactuar en el medio ambiente. También se incluyen algunos residuos similares a los residuos sólidos Urbanos.

Residuos radiactivos.

Materiales que emiten radiactividad.

Residuos tóxicos y peligrosos.

Son considerados en este grupo los que entran dentro de las características especificadas por las diferentes normas medioambientales. Este grupo de residuos exige, en función de sus características físicas o químicas, un proceso de tratamiento, recuperación o eliminación especifica. 


\section{Residuos mineros.}

Los residuos mineros incluyen los materiales que son removidos para ganar acceso a los minerales y todos los residuos provenientes de los procesos mineros. Actualmente, la industria del cobre se encuentra empeñada en la implementación de un manejo apropiado de estos residuos, por lo cual se espera en un futuro próximo contar con estadísticas apropiadas.

Residuos hospitalarios: Restos del trabajo clínico o de investigación. Actualmente el manejo de los residuos hospitalarios no es el más apropiado ya que no existe un reglamento claro al respecto. El manejo de estos residuos es realizado a nivel del generador y no bajo un sistema descentralizado. A nivel del hospital los residuos son generalmente esterilizados.

\section{Cosificación por tipo de manejo}

Se puede clasificar un residuo por presentar alguna característica asociada al manejo que debe ser realizado.

\section{Residuo peligroso.}

Residuos que por su naturaleza son inherentemente peligrosos de manejar y/o disponer y pueden causar muerte, enfermedad; o que son peligrosos para la salud o el medio ambiente cuando son manejados en forma inapropiada.

\section{Residuo inerte.}

Residuo estable en el tiempo, el cual no producirá efectos ambientales apreciables al interactuar en el medio ambiente. 


\subsubsection{Los residuos sólidos orgánicos y su clasificación.}

Según Flores Dante (Flores, 2001, págs. 8-12), ${ }^{15}$ los residuos sólidos son aquellos residuos que provienen de restos de productos de origen orgánico, la mayoría de ellos son biodegradables (se descomponen naturalmente). Se pueden desintegrar $\mathrm{o}$ degradar rápidamente, transformándose en otro tipo de materia orgánica. Ejemplo: los restos de comida, frutas y verduras, carne, huevos, etcétera, o pueden tener un tiempo de degradación más lento, como el cartón y el papel. Se exceptúa de estas propiedades al plástico, porque a pesar de tener su origen en un compuesto orgánico, posee una estructura molecular más complicada.

Existen muchas formas de clasificación de los residuos sólidos orgánicos, sin embargo, las dos más conocidas están relacionadas con su fuente de generación y con su naturaleza y/o características físicas.

Según su fuente de generación: los residuos sólidos orgánicos según su fuente se clasifican en:

Residuos sólidos orgánicos provenientes del barrido de las calles: consideramos dentro de esta fuente a los residuos almacenados también en las papeleras públicas; su contenido es muy variado, pueden encontrarse desde restos de frutas hasta papeles y plásticos. En este caso, sus posibilidades de aprovechamiento son un poco más limitadas, por la dificultad que representa llevar adelante el proceso de separación física.

Residuos sólidos orgánicos institucionales: residuos provenientes de instituciones públicas (gubernamentales) y privadas. Se caracteriza mayormente por contener papeles y cartones y también residuos de alimentos provenientes de los comedores institucionales.

Residuos sólidos de mercados: son aquellos residuos provenientes de mercados de abastos y otros centros de venta de productos alimenticios. Es una buena fuente para el aprovechamiento de orgánicos y en especial para la elaboración de compost y fertilizante orgánico.

15 Flores, D. (2001) El aprovechamiento de los residuos sólidos orgánicos. Guía Práctica No.2. 8-12. 
Residuos sólidos orgánicos de origen comercial: son residuos provenientes de los establecimientos comerciales, entre los que se incluyen tiendas y restaurantes. Estos últimos son la fuente con mayor generación de residuos orgánicos debido al tipo de servicio que ofrecen como es la venta de comidas. Requieren de un trato especial por ser fuente aprovechable para la alimentación de ganado porcino.

Residuos sólidos orgánicos domiciliarios: son residuos provenientes de hogares, cuya característica puede ser variada, pero que mayormente contienen restos de verduras, frutas, residuos de alimentos preparados, podas de jardín y papeles. Representa un gran potencial para su aprovechamiento en los departamentos del país.

\subsubsection{Otras iniciativas ambientales.}

La regla de las $3 \mathrm{R}^{16}$ (Martinez \& Bigues, 2009) es una propuesta que tiene como concepto establecer estrategias al manejo de residuos sólidos priorizando la reducción en volumen con la finalidad de ser sustentables con el medio ambiente (Green Peaje). Dicha propuesta establece 3 acciones: reduce, reúsa y recicla. Reducir se define como el proceso por el cual se disminuye la generación de residuos (independientemente de su estado físico y peligrosidad) dentro del proceso productivo de una empresa, las consecuencias pueden generar, en primer lugar, una reducción en los costes directos del proceso de producción. Al tener menos residuos generados, la empresa debe invertir menos en su gestión. En segundo lugar, se genera menos impacto ambiental en el medioambiente. Reúsa, esta se basa en reutilizar un objeto o sobrantes de cultivos para darle una segunda vida útil. Todos los materiales o bienes pueden tener más de una vida útil, bien sea reparándolos para un mismo uso o complementándolos para un uso diferente. Recicla, este concepto es el más popular

16 Martinez, S. \& Bigues J. (2009). El Libro de las 3R: Reducir, Reutilizar, Reciclar. Barcelona. 


\section{CAPÍTULO 2. METODOLOGÍA DE INVESTIGACIÓN}

\subsection{Planteamiento De La Investigación}

En dicho capitulo se muestra el planteamiento propuesto para la presente investigación, la cual a través de forma organizada se aplicó para resolver la hipótesis planteada para nuestro siguiente estudio.

\subsubsection{Propósito de la investigación}

El propósito de esta investigación es identificar el desarrollo de ventajas competitivas desde el enfoque de la implementación de gestión integral de residuos sólidos orgánicos en las agroexportadoras de café en la región San Martin

Para nuestro siguiente estudio tuvimos que entrevistar a los principales actores de la materia agroexportadora en este sector que permitieron el desarrollo de la presente investigación tal como, representantes de organismos públicos, certificadores privados, representantes de las empresas exportadoras de café, en suma y productores de la región de San Martin.

Los participantes son una muestra representativa del sector que nos compartieron con sus conocimientos y experiencia con la finalidad de enriquecer nuestra exploración

El instrumento utilizado para la investigación fueron las entrevistas semiestructuradas.

Adicionalmente, problema surge por el poco compromiso que existe de los directivos de las empresas exportadoras para implementar el sistema de gestión de residuos sólidos orgánicos en sus operaciones. Teniendo en cuenta que en la actualidad grandes empresas se ven cuestionadas por las malas prácticas empresariales que generan insatisfacción en las comunidades.

A esto se le suma la poca información que se tiene sobre los beneficios que genera la implementación del sistema de gestión de residuos sólidos orgánicos, ya que no saben cómo determinar que la inversión en actividades de revalorización puede generar un mayor retorno de la inversión. 
Otro punto a evaluar es el rol del estado y su poca difusión sobre temas relacionados a las prácticas de implementación del sistema de gestión de residuos sólidos orgánicos, ya que al no determinar las pautas básicas sobre las relaciones medioambientales con la comunidad dificulta la identificación de ventajas competitivas en las agroexportadoras de café de la región San Martin.

\subsubsection{Tipo de investigación}

La investigación se basó en la teoría fundamentada y se trabajó bajo la investigación cualitativa descriptiva-explicativa, puesto que se era necesario conocer acerca de las ventajas competitivas desde el enfoque de la gestión integral de residuos sólidos orgánicos en las agroexportadoras de café en la región San Martin, por ende procedimos a coordinar una muestra representativa de los segmentos que se seleccionaron para examinar los puntos de vista de los diferentes segmentos, se realizó entrevistas a profundidad para conocer las distintas experiencias que los rodean o perciban para conseguir el objetivo de la investigación.

Por otra parte, todos los segmentos de nuestras entrevistas no estuvieron manipulados y se encontraban dispuestos a compartir sus conocimientos, experiencias, y respondiendo de manera concreta a cada una de nuestras interrogantes.

\subsubsection{Preguntas de la investigación}

Al definir nuestro marco teórico, elaboraremos nuestra pregunta de investigación, por lo que se tomó en cuenta las opiniones de los representantes de cada segmento elegido para identificar y responder la pregunta que detallamos a continuación:

\subsubsection{Pregunta General.}

¿Cuáles son las ventajas competitivas que se generan desde el enfoque de implementación de la gestión integral de residuos sólidos orgánicos en las agroexportadoras de café en la región San Martin? 


\subsubsection{Preguntas Específicas.}

- ¿Cuáles es el nivel de conocimiento relacionado a la gestión de residuos sólidos orgánicos y su impacto en el medio ambiente de los agroexportadores de café en la región San Martin?

- ¿Cuáles solo los lineamientos técnico que emplean en la gestión de los residuos sólidos orgánicos para su valorización de los agroexportadores de café en la región San Martin?

- ¿Cuáles son las alternativas de negocios a desarrollar en la implementación de la gestión de residuos sólidos orgánicos de los agroexportadores de café en la región de San Martin?

\subsubsection{Objetivos de la Investigación.}

\subsubsection{Objetivo General.}

Identificar las ventajas competitivas que se generan desde el enfoque de implementación de la gestión integral de residuos sólidos orgánicos en las agroexportadoras de café en la región San Martin.

\subsubsection{Objetivos Específicos.}

- Identificar los niveles de conocimiento relacionados a la gestión de residuos sólidos orgánicos y su impacto en el medio de los agroexportadores de café en la región San Martin.

- Definir los lineamientos técnico que emplean en la gestión de los residuos sólidos orgánicos para su valorización de los agroexportadores de café en la región San Martin.

- Identificar las alternativas de negocios a desarrollar en la implementación de la gestión de residuos sólidos orgánicos de los agroexportadores de café en la región de San Martin.

\subsubsection{Hipótesis de la Investigación.}

\subsubsection{Hipótesis General.}

La implementación de la gestión de residuos sólidos orgánicos genera ventajas competitivas en las agroexportadoras de café en la región San Martin. 


\subsubsection{Hipótesis Específicas.}

- Las agroexportadoras de café en la región San Martin tienen conocimiento relacionado a la gestión de residuos sólidos orgánicos y su impacto en el medioambiente.

- La gestión de residuos sólidos orgánicos de los agroexportadores de café de la región San Martin establece lineamientos técnicos para generar valorización.

- Las agroexportadoras de café en la región San Martin desarrollan alternativas de negocios derivados de la implementación de la gestión integral de residuos sólidos orgánicos.

\subsection{Contexto}

El inicio de la investigación se dio a través de nuestro propio entorno con los contactos más cercano que podíamos tener, se envió por medio de las diferentes redes sociales las primeras invitaciones para aportar con su entrevista a nuestra investigación, como es de esperarse se obtuvieron respuesta inmediatas y satisfactorias, luego de obtener la primera entrevista, se tenía que buscar más entrevistas de cada uno de los segmentos, necesitábamos conocer más de ellos así que se tuvo que indagar en las páginas webs para conectar con ellos, esta tarea no fue tan sencilla como la primera, estaba vez se tuvo no solo que buscar los contactos, sino sus correos, escribir a las persona correctas y tener que visitar las instituciones para sacar una cita o un simple correo, muchos de ellos no respondieron, algunos correos no eran los correctos y en otros casos se debía adecuar a las condiciones, horarios y fechas disponibles de los entrevistados, la gran mayoría de las entrevistas fueron de manera personal, pero también se realizó una entrevistas vía Skype, además se puede resaltar que muchos de los entrevistados se tomaron el tiempo para llamarnos y coordinar de forma correcta las entrevistas.

Durante las entrevistas de nuestros participantes, ellos se mostraron en todo momento con toda la disponibilidad para apoyarnos en nuestra investigación, algunos nos invitaron a sus oficinas recibiéndonos de manera agradable donde pudimos utilizar todos los recursos como laptops o proyectores para visualizar mejor y entender lo que se quería explicar, otros de nuestros entrevistados proporcionaron información de manera impresa con la finalidad de apoyarnos con la investigación, algunos de ellos nos brindaron contactos adicionales para profundizar el estudio de nuestra investigación. En un caso como el segmento del estado tuvimos que coordinar una entrevista con un conocido de SUNAT que también conoce mucho sobre el tema la cual fue de mucha ayuda. 
En suma, logramos la participación de los segmentos elegidos, donde pudimos recolectar la información requerida para nuestra investigación, en algunas oportunidades no se concretaron algunas entrevistas por el tiempo, las condiciones del sector, pero se logró hacer el análisis de las entrevistas obtenidas.

\subsection{Muestra o Participantes}

La muestra que procedimos a elegir para realizar las entrevistas es representativa de cada sector, realizamos la segmentación en cinco grupos como son los organismos públicos relacionados con el sector, representantes de organismos públicos, certificadores privados, representantes de las empresas exportadoras de café, en suma y productores de la región de San Martin, en efecto la muestra seleccionada y los participantes elegidos respaldaron y lograron responder al objetivo de la investigación, nuestra muestra contiene 9 entrevistas, una de ellas vía Skype

\subsection{Diseño o Abordaje Principal}

\subsubsection{Identificación de la estructura de la entrevista.}

En primer lugar, se elaboró la herramienta que es el cuestionario y se utilizó la técnica de la entrevista semiestructura para dar inicio a cada una de nuestras conversaciones, para todas ellas se llevó la guía de preguntas que se realizarían, pero cuando comenzamos con el diálogo surgieron otras interrogantes que se debía contestar o repreguntar, y mientras el entrevistado respondía, algunos de los entrevistados incluso nos realizaron preguntas, con el fin de instruirnos con pautas para brindarnos su apoyo con el estudio de investigación. En la dicho proceso utilizamos la teoría fundamenta, debido a que después de la recolección de datos con las herramientas y técnicas adecuadas se coincidió a través de la inducción a formar una teoría explicativa acerca del problema planteado. 


\subsubsection{Guía de preguntas.}

La guía de preguntas fue elaborada de manera propia antes de realizarse la entrevista, en la siguiente investigación se elaboró tres categorías de preguntas, debido a que existían cinco segmentos seleccionados para este estudio, las preguntas que se realizaron fueron desde lo general a lo específico, en algunas oportunidades los entrevistados han respondido ya por adelantado algunas de nuestra preguntas preparadas en la guía

\subsubsection{Segmentos.}

Clasificamos en cinco segmentos a nuestros entrevistados

Segmento 1: Productores de Café Orgánico

Segmento 2: Exportadores de productos orgánicos

Segmento 3: Estado

Segmento 4: Certificadores

Segmento 5: Gremio

\subsubsection{Categorías.}

Se determinaron tres categorías

- Categoría 1: Impacto medioambiental

- Categoría 2: Métodos de valorización de residuos

- Categoría 3: Oportunidad de desarrollo económico

\subsubsection{El instrumento de investigación.}

El instrumento que nos ayudó a realizar el registro de información y recolectar de datos fue el cuestionario, con este instrumento se logró realizar las entrevistas personales y virtuales, ya 
que una de ellas se realizó vía Skype debido a que el productor se encontraba en la provincia de San Martin

Las entrevistas que se desarrollaron fueron entrevistas a profundidad, con ellas se podía conocer las opiniones y experiencias de los expertos elegidos para nuestra investigación, las preguntas elaboradas correspondían a cada una de las categorías que se requería investigar, las entrevistas personales y vía Skype fueron grabadas, no se tuvo ninguna dificultad en el desarrollo de ninguna de ellas. El tiempo mínimo de las entrevistas duro quince minutos y el máximo tiempo de entrevista duro 30 minutos, la idea era agilizar el tiempo de los entrevistados e ir directo a las preguntas de su categoría

\subsection{Procedimientos}

Para llegar a los resultados de la investigación y poder validar o rechazar la hipótesis, se tuvo que realizar un proceso el cual lo explicaremos detalladamente:

- Tuvimos que definir los segmentos que eran necesario entrevistas, luego de elegir los estos para contar con un mayor resultado de investigación, que en nuestro caso fueron cinco, se propuso las categorías las cuales eran tres basados en los objetivos planteados.

- Luego de ello, asignamos las preguntas por las diferentes categorías, estas fueron diseñadas de acuerdo al segmento y la categoría que habíamos planteado, después se realizó una bitácora donde conforme se desarrollaban las entrevistas se iban colocando las observaciones, dificultades y otros aspectos importantes para investigación.

- Posteriormente, se fueron realizando las entrevistas y cada respuesta se transcribía en la matriz por categoría y segmento al cual pertenecía, las entrevistas se dieron entre los meses de Marzo y Mayo del presente año con la finalidad de contar con el trabajo listo a fines de Junio, dichas entrevistas iban siendo analizadas, investigadas y se extrajo los conceptos e información más relevante para el trabajo de investigación

- Finalizada las entrevistas, se realizó un análisis de cada una de ellas, se obtuvo un total de siete entrevistas, una de las cuales fue vía Skype, con los datos obtenidos se realizaron las conclusiones por cada segmento y se dieron una valoración junto con un código, la cual fue 
dada de acuerdo a la situación en que se dio la entrevista, el manejos y experiencia en el sector, como se desarrolló la entrevista y forma de la recolección.

Esta matriz por categorías y segmento será la que nos ayude con el análisis de datos y resultados de nuestra investigación. Así mismo, con la discusión de resultados y la generación de las conclusiones, donde finalmente podremos concluir con una nueva hipótesis después de los resultados obtenidos. 


\section{CAPÍTULO 3. ANÁLISIS DE DATOS Y RESULTADOS}

\subsection{Segmento Uno: Agricultores de Café}

Categoría 1: Impacto Medioambiental

En esta categoría identificamos que el entrevistado tiene como concepto de gestión de residuos sólidos orgánicos la reutilización de los residuos con la finalidad de evitar que dichos residuos contaminen el suelo y perjudiquen la tierra que posteriormente será usada.

Adicionalmente consideran que la falta de conocimiento sobre los temas relacionados a la gestión de residuos es limitante para su implementación, pero tienen claro que esta gestión puede ser bien aprovechada e impactaría positivamente en la imagen corporativa.

Categoría 2: Método de valorización de residuos

El entrevistado tiene claro que el método de valorización de residuos permite generar recursos económicos y ya tienen identificado, en el proceso, a la pulpa de café como el residuo que más se genera, además, utilizan el método de compostaje para la elaboración de abono.

Categoría 3: Oportunidades de desarrollo económico

El entrevistado identifica a la pulpa del café como sub producto que pueden reutilizarse para la elaboración de abono o como alimento para animales

\subsection{Segmento Dos: Exportadores de Café}

Categoría 1: Impacto Medioambiental

La CEO Annie Pinedo de la organización Picky Foods S.A nos indica que el concepto de gestión de residuos sólidos orgánicos que se tiene está enfocado en su totalidad a reutilización de los residuos y de esta forma contribuir con la protección del medio ambiente, además considera que mucho exportadores tienen las intenciones implementar algún programa de 
gestión de residuos, buscando las alternativas más eficientes, siguiendo parámetros ya establecidos en otros casos, así evitar se generen gastos. También considera que la oportunidad de realizar una implementación ayudara a posicionarlos como una empresa socialmente responsable que genera valor y contribuye con el medio ambiente, impactando positivamente con la imagen de la organización.

Por su parte el Gerente General Jimmy Rojas de la cooperativa agraria APROECO menciona que las acciones que toman en la gestión de residuo solido están directamente relacionado con la reutilización de los subproductos que se genera de la actividad cafetalera, con la finalidad de incentivar y generar conciencia sobre el impacto en el medio ambiente. Considera también que algunos exportadores si se preocupan por mantener alguna actividad relacionada a la gestión de residuos sólidos porque tienen claro que esta acción les permite contribuir con la sociedad, pero otros exportadores se ven condicionados por algún requerimiento legal o exigencia de algún cliente, en cualquiera de los casos si tiene claro que la limitación a realizar un correcta implementación se debe a la poca información que se tiene sobre las practicas o alternativas dentro de la gestión de los residuos orgánicos y los beneficios que se pueden obtener. Por otra parte concluye que la implementación de una gestión de residuos sólidos orgánicos ayudaría a los exportadores a generar mayor oportunidades y permitiría contar con una ventaja frente a sus competidores.

Como podemos observar, ambos entrevistados coinciden que cuando hablamos de gestión de residuos sólidos orgánicos, el primer concepto que se identifica es la reutilización de los residuos. Además concluyen que algunos exportadores creen que implementar la gestión de residuos orgánicos podría generar gastos, otros si están convencidos que estas actividades contribuyen con la sociedad, pero que la poca información que se tiene sobre estas prácticas, es una limitante para realizar un correcta implementación de residuos sólidos orgánicos.

Por otra parte los entrevistados tienen claro que los beneficios al implementar la gestión de residuos sólidos orgánicos impactaran positivamente en la imagen de los exportadores generando mayores ventas.

Categoría 2: Método de valorización de residuos 
La CEO Annie Pinedo de la organización Picky Foods S.A. y el Gerente General Jimmy Rojas de la cooperativa agraria APROECO coinciden que la valorización de residuos consiste en la generación de ingresos por medio de la reutilización; además tienen identificado al proceso de despulpado como la actividad donde se genera mayor cantidad de residuo solido orgánico y que puede ser aprovechado en la elaboración de abono mediante el método de compostaje.

Categoría 3: Oportunidades de desarrollo económico

Para ambos entrevistados una oportunidad de negocio se puede desarrollar aprovechando la generación de los residuos sólidos orgánicos obtenidos por el proceso de despulpado, ambos consideran que la elaboración de abono es la opción fácil de implementar y que demanda menos recursos, sin embargo Annie Pinedo nos comenta sobre otras alternativas, como el caso del método de lombricultura y fuentes de energías renovables.

\subsection{Segmento Tres: Estado}

Categoría 1: Exportadores de café

Mauro Burga, especialista de Aduanas en SUNAT, considera que en algunos los agroexportadores de café si implementan la gestión de residuos sólidos orgánicos con la finalidad de apoyar al medio ambiente y que estas prácticas contribuyen a mejorar la imagen y crear valores entre los trabajadores.

Desde SUNAT se promueve el cuidado del medio ambiente es por ellos que apoyan a los productores que elaboran productos orgánico y convencionales, así de esta manera poder diferenciarse.

Categoría 2: Método de valorización de residuos

Según el especialista Mauro Burga, se fomentan programas de segregación de residuos sólidos fomentando siempre el cuidado del medio ambiente, así mismo manifiesta que los controles y fiscalización se realizan por parte SENASA pero también existe la ley No 29196, Ley de Promoción de la Producción Orgánica y Ecológica. 


\subsection{Segmento Cuatro: Certificadoras}

Categoría 1: Exportadores de café

Jose Farfán, consultor senior en Avanza Sostenible nos comenta que los agroexportadores cada vez estas más familiarizados con los conceptos relacionados a la gestión de residuos sólidos y cuentan con más información, esto les permite implementar diversas acciones que contribuyen a las prácticas amigables con el medio ambiente. Por otra parte considera la falta de voluntad e iniciativa como la principal limitación, debido a que los agroexportadores tienen accesos a fuentes de información y a la posibilidad de asesorarse con especialistas en temas de gestión de residuos sólidos orgánicos, además, estas buenas prácticas medioambientales nos ayuda a reducir o eliminar aspectos e impactos ambientales los cuales son generados en las actividades cafetaleras.

Por su parte, Oscar Mestanza KAM en Control Unión Perú SAC, también considera que los agroexportadores de café cuentan con mayor información sobre los temas relacionados a la gestión de residuos sólidos y esto les permite conocer y relacionarse de maneras más activa con los temas coyunturales relacionados al cuidado del medioambiente; pero también puede observar que debido a la falta de iniciativa de muchos de los agroexportadores de café, la implementación de gestión de residuos sólidos orgánicos se termina ejecutando considerando diversos parámetros, muchos de ellos no estandarizados poniendo en riesgo la principal finalidad de ayuda y aportar al medioambiente.

Oscar Mestanza también considera que la gestión de residuos sólidos orgánicos en las actividades de agro exportación contribuye con la reducción de los impactos ambientales, además posiciona a las agroexportadoras como una empresa responsable con el medioambiente, mejorando su imagen empresarial y diferenciándolos frente a sus competidores.

Categoría 2: Método de valorización de residuos

Jose Farfán, consultor senior en Avanza Sostenible manifiesta que las técnicas de reutilización de residuos sólidos orgánicos que más emplean los agroexportadores de café es la separación de los residuos orgánicos y que no existe una certificación obligatoria que garantice la correcta aplicación de un método de valorización, pero si se puede optar con alinearse a estándares 
internacionales como la ISO 14001 Norma Internacional de Sistemas de Gestión Ambiental (SGA)

Oscar Mestanza en este punto considera que los agroexportadores de café, además de realizar la separación de los residuos, también emplean la elaboración de compostaje como método de valorización de residuos orgánicos, con el fin de generar beneficios económicos.

\subsection{Segmento Cinco: Gremios}

Categoría 1: Exportadores de café

Rolando Herrera, especialista en temas de producción de café, como socio de ADEX nos comenta que los agroexportadores de café si implementan la gestión de los residuos sólidos orgánicos, ya que se encuentran cada vez más familiarizados con los temas, pero por otra parte menciona que la informalidad puede ser determinante al momento que el agroexportador decida si incursionar en temas de responsabilidad medioambiental. Pero si tiene identificado que esta actividad es una oportunidad para mejorar las relaciones comerciales, mejorar la imagen de la empresa, apoyar al medio ambiente y generar nuevos modelos de negocio. También nos informa que ADEX, como gremio, apoya en la venta y comercialización a los agroexportadores que mantengas buenas prácticas medioambientales.

Categoría 2: Método de valorización de residuos

La técnica que tienen identificada como la más empleada por los agroexportadores es el método de compostaje, el cual permite aprovechar los residuos sólidos orgánicos en un producto estable y utilizable para la agricultura. Pero también en ADEX se fomenta los programas para la segregación de residuos sólidos y reutilización de residuos con la finalidad de promover e incentivar a los exportadores en los hábitos de cuidado con el medio ambiente.

Rolando Herrera nos manifiesta adicionalmente que tiene identificado los subproductos generados en el cultivo de café que son: mucílago, borra de café y ripios de café, como productos con gran capacidad para su reutilización. 
Categoría 3: Oportunidades de desarrollo económico

El especialista Rolando Herrera, tiene identificado las oportunidades de negocio que se puede generar a partir de la implementación de la gestión de residuos sólidos orgánicos, la primera opción es la generación de fuentes de energías renovables, así evitar que los residuos orgánicos se desechen en los rellenos sanitarios contaminando el medio ambiente, y la segunda opción será la elaboración de compost para la agricultura. 


\section{CAPÍTULO 4. DISCUSIÓN DE RESULTADOS}

En este presente capítulo desarrollaremos de acuerdo a los objetivos planteados y los resultados encontrados en cada categoría de preguntas, debatiremos los resultados encontrados verificando la información hallada fundamentada en el análisis de campo y el marco teórico, adicionalmente se evaluará los alcances de la investigación teóricas y prácticas, donde se verificara si se alcanzó los objetivos de la investigación, considerando las limitaciones, barreras y brechas que tuvo la investigación.

\subsection{Discusión de Resultados}

Detallaremos la discusión de resultados por categorías.

\subsubsection{Discusión de resultados de Categoría 1: Impacto medioambiental.}

De los cinco segmentos considerados en esta categoría, el segmento 1 y 2 tienen como concepto sobre la gestión de residuos sólidos orgánicos, la reutilización de los residuos, además tienen claro que implementar esta gestión genera beneficios como mejorar la imagen frente a sus clientes y competidores, viéndose reflejado en el incremente de las ventas. Pero también consideran que no todos los agricultores y exportadores se preocupan por implementar la gestión de residuos sólidos orgánicos, según ellos debido a la falta de conocimiento y poca información, además ven estas prácticas como un gasto.

Por otra parte; los segmentos 3, 4 y 5, consideran muchos agroexportadores cuentan con el conocimiento sobre los temas relacionados a la implementación de gestión de residuos sólidos orgánicos, además tienen claro que estas prácticas contribuye con el cuidado del medioambiente y ayudan a mejorar la imagen de quienes lo implementan. El segmento 4 indica que hay un grupo de agroexportadores que debido a la falta de iniciativa ven postergada la posibilidad de aplicar buenas prácticas medioambientales. 


\subsubsection{Discusión de resultados de Categoría 2: Método de Valorización de Residuos.}

Para los segmentos 1 y 2 , el concepto de valorización de residuos está relacionado directamente con la obtención de ingresos y tienen identificado que en la elaboración del café, el proceso de despulpado es donde se genera la mayor cantidad de residuos sólidos orgánicos la cual puede ser aprovechado para la elaboración de abono a través del método de compostaje, que permitirá se reutilizado en la misma tierra.

Los segmentos 4 y 5 , indican que las técnicas de reutilización de residuos sólidos orgánicos más empleadas por los agroexportadores es el método de compostaje.

Los segmentos 3 y 5 , mencionan que los programas que se fomentan, relacionados a la valorización de residuos sólidos orgánicos, son la segregación de residuos; mientras que el segmento 4 nos indica que no existe una certificación obligatoria que nos garantice una correcta forma de aplicar un método de valorización, sin embargo, se puede tomar como referencia los estándares internacionales bajo el ISO 14001

\subsubsection{Discusión de resultados de Categoría 3: Oportunidades de Desarrollo Económico}

Los segmentos 1 y 2 , tienen identificado dentro del proceso de elaboración de café que los subproductos más relevantes que se generan son: borra de café, tallo y pulpa de café que representa casi el $45 \%$ del fruto. También tienen claro que la elaboración de abono y es una alternativa para generar un oportunidad de negocio.

El segmento 1 considera que la pulpa de café puede servir como alimento para animales, generando un oportunidad de negocio; y el segmento 2 considera que al método de lombricultivo y la generación de fuentes de energías renovables como posibles oportunidades de desarrollo de negocio. 


\subsection{Hallazgos de la investigación}

Después de todas nuestras entrevistas realizadas, el análisis de los resultados y el marco teórico surgieron algunos hallazgos en nuestra investigación a partir de los datos analizados se planificará una interpretación, a continuación, detallaremos algunos:

- Dentro de la categoría 3 oportunidad de desarrollo económico se puede identificar que los segmentos 1 y 2 tienen como concepto, para la valorización de los residuos, la elaboración de abono, a través del método de compostaje, sin embargo, se podría desarrollar otras oportunidades como por ejemplo: la generación de fuentes de energía renovable, donde podrían intervenir el estado y las certificadoras, definiendo los lineamientos técnicos.

- Los segmentos 1 y 2 no tienen identificado todos los subproductos que se generan en el proceso de elaboración de café, reduciendo sus oportunidades de valorización de residuos; a diferencia de los gremios, que tienen identifico otros subproductos: ripio, mucilago. Los cuales podrían ser reutilizados.

\subsection{Barreras de la investigación}

Después de realizar la investigación llegamos a esta parte de la investigación donde podemos describiremos algunas restricciones que fueron obstáculos para nuestro estudio, pero no afectaron dejar de cumplir con los objetivos planteados.

- El segmento 1 generó dificultad, ya que fue difícil concretar entrevistas con los productores de la región San Martin debido a esto, tuvimos que coordinar una entrevista vía Skype con la finalidad de cumplir con los parámetros y apoyo mucho a las respuestas de los objetivos indicados

- El segmento 3 genero mucha mayor dificultad debido a que se había coordinado una entrevista con un personal de SENASA del cual cuando nuevamente realizamos contacto nos indicaron que ya no laborada más en dicha entidad.

- La cantidad de muestra proyectada era de 10 entrevistados, 2 por segmento pero sólo se logró entrevistar a 7 entrevistados, pero esta barrera no impidió que se logre recoger los datos necesarios para realizar el análisis y responder a los objetivos planteados. 
- En general hoy en día es muy complicado contar con entrevistas y que presente unos 30 minutos de su tiempo, y más aún que sea posible grabarlos pero realmente lo conseguimos con el objetivo de lograr una gran investigación y cumplir con los objetivos indicados en nuestro trabajo.

\subsection{Brechas de la investigación}

Las brechas en nuestro trabajo de investigación no fueron ningún impedimento, a pesar de no haber complicado con las entrevistas planeadas se cumplió con el objetivo que fue posible realizar el análisis de la investigación, por otro lado, uno de los entrevistados fueron atendidas por Skype, podemos concluir que no contamos con ninguna brecha en la investigación. 


\section{CONCLUSIONES}

El propósito de investigación nació del problema a estudiar, de este modo surgió la pregunta de investigación: ¿Cuáles son las ventajas competitivas que se generan desde el enfoque de implementación de la gestión integral de residuos sólidos orgánicos en las agroexportadoras de café en la región San Martin?

La hipótesis inicial planteada es saber si la implementación de la gestión de residuos sólidos orgánicos genera ventajas competitivas en las agroexportadoras de café en la región San Martin, se valida la hipótesis parcialmente:

1. Se concluye que el nivel de conocimiento sobre los temar relacionados a la gestión de residuos sólidos orgánicos y su impacto en el medioambiente son conceptos que los agroexportadores dominan parcialmente, debido a que estos conceptos estas limitados a al conocimiento empírico y a los temas coyunturales. En la actualidad existes lineamientos para la implementación de gestión de residuos sólidos orgánicos, como la ISO 140001 Norma Internacional de Sistemas de Gestión Ambiental (SGA) y la Ley No 29196 Ley de Promoción de la Producción Orgánica o Ecológica, los cuales nos brindan capacidad técnica en beneficio de las agro exportación y el cuidado del medioambiente.

2. Se concluye que los lineamientos técnicos que emplean en la gestión de los residuos sólidos orgánicos para su valorización de los agroexportadores de café en la región San Martin no están debidamente implementados, ya que se tiene como única alternativa elaboración de abono bajo el método del compostaje. Esto refleja que no conocen sobre otros métodos de valorización que podrían aprovechar otros subproductos derivados de la elaboración de café.

3. Se concluye que las alternativas de negocios a desarrollar en la implementación de la gestión de residuos sólidos orgánicos de los agroexportadores de café en la región de San Martin, no están siendo aprovechadas al máximo, ya que observamos que los agroexportadores no tienen identificados al 100\% los subproductos que se generan en 
el proceso de elaboración de café, los cuales podrían ser aprovechados para generar nuevas oportunidades de negocio. 


\section{RECOMENDACIONES}

1. Los gremios, con apoyo del estado es necesario que desarrollen e implementen nuevas alternativas para la valorización de residuos sólidos orgánicos, aprovechando al 100\% los subproductos que generan la elaboración de café, casos como la generación de energía renovable podrían desarrollar mejor fuentes de ingreso para los agroexportadores.

2. Las asociaciones y/o cooperativas, en colaboración con los gremios y certificadoras, inviertan en conocimiento, con la finalidad de capacitar a sus productores y trabajadores orientados a la implementación de la gestión de residuos sólidos orgánicos. 


\section{REFERENCIAS BIBLIOGRÁFICAS}

Dr. Roberto Hernandez Sampieri (2010). Metodología de la Investigación. Sexta Edición. México D.F

Diario Gestión - Grupo El Comercio (2011). Exportaciones de Café llegarían a USD 1,100 millones este año. En: Diario Gestión, 12 de setiembre

Diario Gestión - Grupo El Comercio (2018). Producción se recupera por cuarto año consecutivo. En: Diario Gestión, 06 de Marzo

La Agro exportación en el Perú (2015). Recuperado de http:/www.larevistaagraria.info/sites/default/files//revista/LRA173/LRA173 Agroexportacio n MesaRedonda.pdf [Consulta: 05 de Abril de 2018]

Ministerio del Ambiente. Ley General de Residuos Sólidos. Recuperado de: http://sinia.minam.gob.pe/normas/ley-general-residuos-solidos [Consulta: 13 de mayo de 2018]

Alaba, L. (2013). Gestión de Aprovechamiento de los Residuos Sólidos en la Región Cajamarca. (Monográfico de Licenciatura, Faculta de Ciencias Agrarias, Universidad Nacional de Cajamarca. Cajamarca, Perú)

Flores, D. (2001) El aprovechamiento de los residuos sólidos orgánicos. Guía Práctica No.2. 8-12.

Naciones Unidas. Población en Crecimiento. Recuperado de: http://www.un.org/es/sections/issues-depth/population/index.html [Consulta: 13 de mayo de 2018]

Ministerio de Comercio Exterior y Turismo (MINCETUR). (2017). Guía de Requisitos Sanitarios y Fitosanitarios para la Agro Exportación a la Unión Europea. Recuperado: 
https://www.mincetur.gob.pe/wpcontent/uploads/documentos/comercio exterior/medidas Sa nitarias_Fitosanitarias/Guia_UE_Alta.pdf [Consulta: 15 de abril de 2018]

Nelson Manrique. «Historia de la agro- cultura peruana», en Compendio de historia económica del Perú. Tomo 5. La economía peruana entre la Gran Depre- Sion y el reformismo militar 1930-1980. Lima: IEP/BCR, 2014, p. 161. Recuperado de http://www.bcrp.gob.pe/docs/Publicaciones/libros/historia/5-gran-depresion-y-reformismomilitar.pdf [Consulta: 05 de Abril de 2018]

Producción de Café Orgánico. Recuperado de http://cafe-peruano.com/produccion-de-cafeorganico-peru.php [Consulta: 05 de Abril de 2018]

Rosemary Thor y Geoffrey Bertrán (1985). Crecimiento y políticas en una economía abierta. (pp. 351). Lima: Mosca Azul / Fundación Friedrich Ebert / UP

Jorge Fernández Baca -Fabián Tune (1981). Producción algodonera e industria textil en el Perú. (pp.122). Lima: Desco

Constitución Política del Perú [Const.] (1993). Recuperado de: http://pdba.georgetown.edu/Parties/Peru/Leyes/constitucion.pdf [Consulta: 13 de mayo de 2018]

Anexo estadístico del Compendio de historia económica del Perú. Tomo 3. Economía del periodo colonial tardío. Lima: IEP/BCR, 2010, p. 414. Recuperado de http://www.bcrp.gob.pe/docs/Publicaciones/libros/historia/3-economia-colonial-tardio.pdf [Consulta: 05 Abril de 2018]

El Perú en marcha. Ensayo de geografía económica. Lima: Banco Italiano, 1941, p. 118

Martinez, S. \& Bigues J. (2009). El Libro de las 3R: Reducir, Reutilizar, Reciclar. Barcelona.

Real Academia Española (RAE). (2001). En Diccionario de la lengua española. 22a ed. Recuperado de http://dle.rae.es/?id=1AVkVQV|1Aa47RA [Consulta: 05 de Abril de 2018] 
Real Academia Española (RAE). (2001). En Diccionario de la lengua española. 22a ed. Recuperado de http://dle.rae.es/?id=HKZN9p1 [Consulta: 05 de Abril de 2018] 


\section{ANEXOS}

\section{$\underline{\text { Anexo } 1}$}

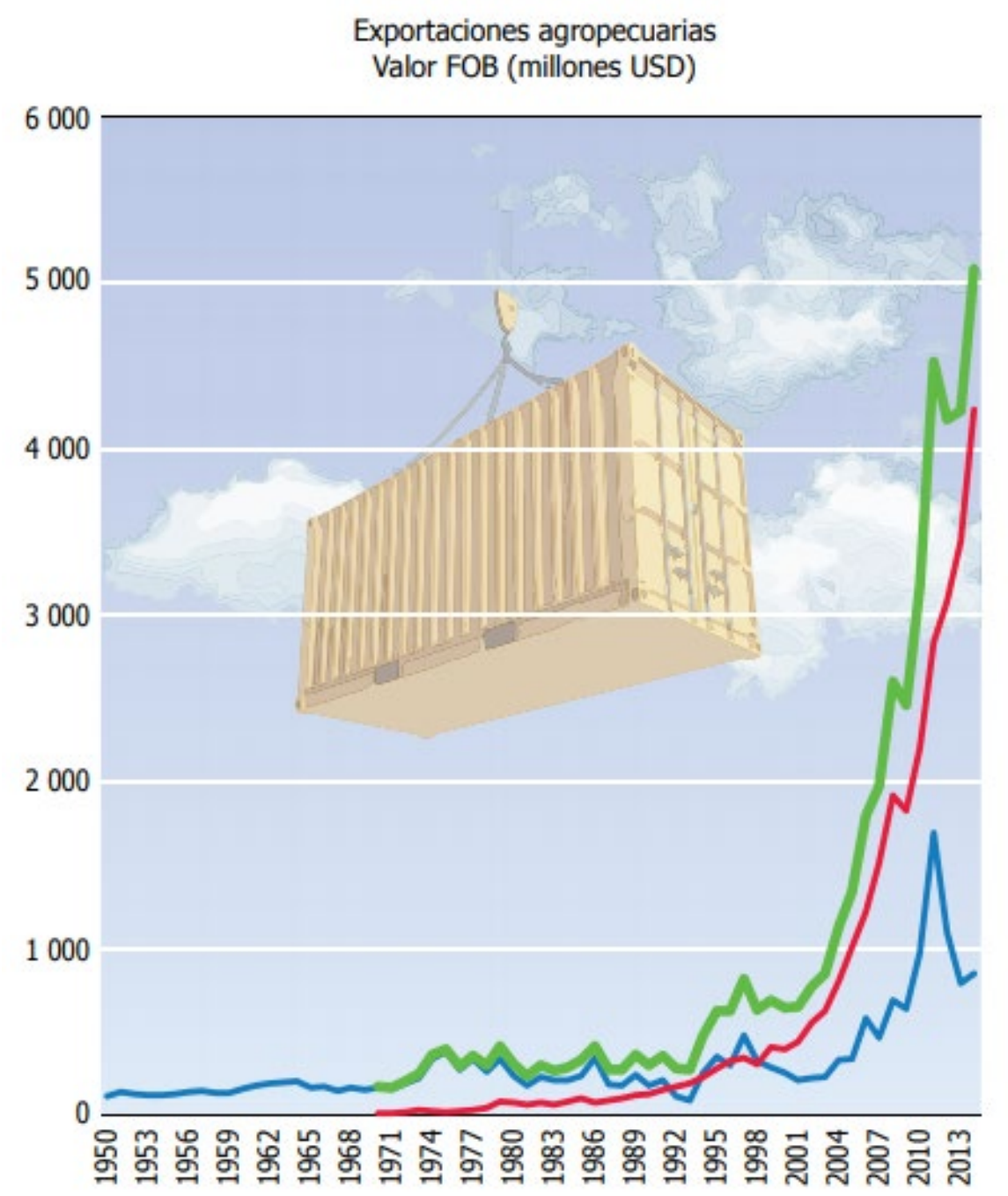

Figura 1: Exportaciones agropecuarias- Valor FOB (Millones USD) según información Fernando Eguren/ Ricardo Marapi 


\section{$\underline{\text { Anexo 2 }}$}

\begin{tabular}{|c|c|c|c|c|c|}
\hline $\begin{array}{l}\text { CATEGORIAS / } \\
\text { SEGMENTOS }\end{array}$ & Agricultores & Exportadores & Estado & Certificadoras & Gremios \\
\hline $\begin{array}{l}\text { Categoria 1- Impacto } \\
\text { medioambiental }\end{array}$ & 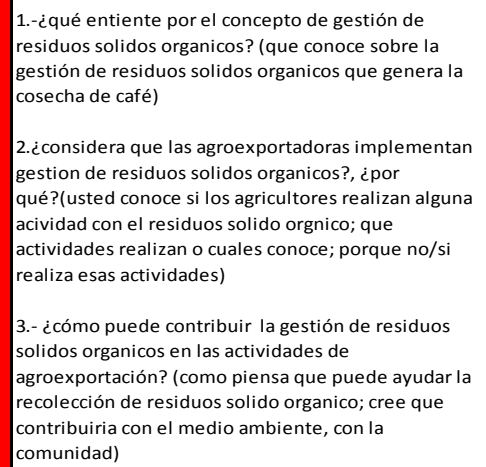 & 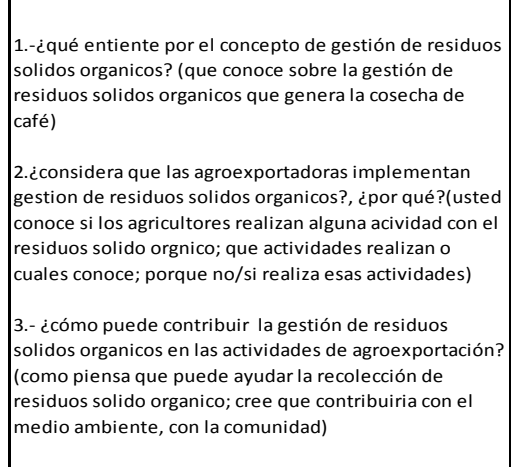 & $\begin{array}{l}\text { 1.- ¿considera que las agroexportadoras } \\
\text { implementan gestion de residuos solidos } \\
\text { organicos?, ¿por qué? } \\
\text { 2.c có́mo puede contribuir con el } \\
\text { medioambiente la gestión de residuos solidos } \\
\text { organicos en las actividades de } \\
\text { agroexportación? } \\
\text { 3.-zićmo promuebe el estado la } \\
\text { implementacion de residuos solidos } \\
\text { organicos? }\end{array}$ & $\begin{array}{l}\text { 1.- ¿considera que las } \\
\text { agroexportadoras implementan } \\
\text { gestion de residuos solidos } \\
\text { organicos?, ipor qué? } \\
\text { 2.-icuáles son las principales } \\
\text { limitaciones para implementar la } \\
\text { gestión de residuos solidos } \\
\text { organicos en las actividades de } \\
\text { agroexportacion? } \\
\text { 3.icómo puede contribuir con el } \\
\text { medioambiente la gestión de } \\
\text { residuos solidos organicos en las } \\
\text { actividadades de agroexportación? }\end{array}$ & $\begin{array}{l}\text { 1.- ¿considera que las } \\
\text { agroexportadoras implementan } \\
\text { gestion de residuos solidos } \\
\text { organicos? ipor qué? } \\
\text { 2.ccómo puede contribuir con el } \\
\text { medioambiente la gestión de } \\
\text { residuos solidos organicos en las } \\
\text { actividades de agroexportación? } 3 \\
\text {--ćcómo promueve los gremios la } \\
\text { implementacion de residuos solidos } \\
\text { organicos? }\end{array}$ \\
\hline $\begin{array}{l}\text { Categoria } 2 \text { - Metodos de } \\
\text { valorización de residuos }\end{array}$ & $\begin{array}{l}\text { 1.-ंqué entiendo por el concepto de valorización de } \\
\text { residuos solidos organicos? (usted sabe si los residuos } \\
\text { solidos organicos pueden ser utilizados para generar } \\
\text { ingresos) } \\
\text { 2--icuál es la etapa en el proceso de agroexportacion } \\
\text { donde se genera mayol residuo solido organico? } \\
\text { (dentro de la actividad que desempeña en que estapa } \\
\text { se genera mayor cantidad de residuo solido organico) } \\
\text { 3-- ¿quué metodo de reutilizacion de residuos solidos } \\
\text { organicos se puede aplicar? (de que forma de } \\
\text { reutilización del residuos solido organico conoce o } \\
\text { cuales aplican) }\end{array}$ & $\begin{array}{l}\text { 1.--ंqué entiendo por el concepto de valorización de } \\
\text { residuos solidos organicos? (usted sabe si los residuos } \\
\text { solidos organicos pueden ser utilizados para generar } \\
\text { ingresos) } \\
\text { 2--icuál es la etapa en el proceso de agroexportacion } \\
\text { donde se genera mayor residuo solido organico? (dentro } \\
\text { de la actividad que desempeña en que estapa se genera } \\
\text { mayor cantidad de residuo solido organico) } \\
\text { 3.- ¿qué metodo de reutilizacion de residuos solidos } \\
\text { organicos se puede aplicar? (de que forma de } \\
\text { reutilización del residuos solido organico conoce o } \\
\text { cuales aplican) }\end{array}$ & $\begin{array}{l}\text { 1.- ¿qué programas fomentan la valorizacion } \\
\text { de residuos solidos organicos en las } \\
\text { agroexportadoras? } \\
\text { 2.-¿qué tipos de control o fiscalizacion aplican? }\end{array}$ & $\begin{array}{l}\text { 1.-zqué tecnicas de reutilizacion de } \\
\text { residuos organicos son las mas } \\
\text { empleadas por las } \\
\text { agroexportadoras? } \\
\text { 2--iqué tipo de certificaciones } \\
\text { existen que garantizan una buena } \\
\text { valorizacion de los residuos solidos } \\
\text { organicos? }\end{array}$ & $\begin{array}{l}\text { 1.- ¿qué técnicas de reutilización de } \\
\text { residuos sólidos orgánicos son las } \\
\text { más empleadas por las } \\
\text { agroexportadoras? } \\
\text { 2. ¿qué programas fomentan la } \\
\text { valorización de residuos sólidos } \\
\text { orgánicos las agroexportadoras? }\end{array}$ \\
\hline $\begin{array}{l}\text { Categoria } 3 \text { - Oportunidad } \\
\text { de desarrollo economico }\end{array}$ & $\begin{array}{l}\text { 1.-¿quué subproductos de generan en el cultivo de } \\
\text { café? (en el cultivo de café que residuos se han } \\
\text { identificado y cuales consideran que pueden ser } \\
\text { reutilizado) } \\
\text { 2.- ¿qué oportunidades de negocio se pueden generar } \\
\text { con los subproducto? (estos residuos que es } \\
\text { identificaron considera que pueden ser utilizados, } \\
\text { comercializados para generar al guna oportunidad de } \\
\text { negocio) }\end{array}$ & $\begin{array}{l}\text { 1.-¿quué subproductos de generan en el cultivo de café? } \\
\text { (en el cultitio de café que residuos se han identificado y } \\
\text { cuales consideran que pueden ser reutilizado) } \\
\text { 2.- ¿qué oportunidades de negocio se pueden generar } \\
\text { con los subproducto? (estos residuos que se } \\
\text { identificaron considera que pueden ser utilizados, } \\
\text { comercializados para generar alguna oportunidad de } \\
\text { negocio) }\end{array}$ & No aplica & No aplica & $\begin{array}{l}\text { 1.- ¿qué subproductos de generan } \\
\text { en el cultivo de café? } \\
\text { 2.- ¿qué oportunidades de negocio } \\
\text { se pueden generar con los } \\
\text { subproductos? }\end{array}$ \\
\hline
\end{tabular}

Figura 2: Matriz Categorias- Segmentos

\section{elaboración propia}




\section{$\underline{\text { Anexo } 3}$}

\section{Cuestionario: Segmento 1}

¿Cuál es su cargo en la asociación y cuánto tiempo viene desempeñándose en él?

¿Qué entiende por el concepto de gestión de residuos sólidos orgánicos?

¿Usted considera que las agroexportadoras implementan gestión de residuos sólidos orgánicos?, ¿Por qué?

¿Cómo puede contribuir la gestión de residuos sólidos orgánicos en las actividades de agro exportación?

¿Qué entiendo por el concepto de valorización de residuos sólidos orgánicos?

¿Cuál es la etapa en el proceso de agro exportación donde se genera mayor residuo solido orgánico?

¿Qué método de reutilización de residuos sólidos orgánicos se puede aplicar?

¿Qué subproductos de generan en el cultivo de café que puedan reutilizarse?

¿Qué oportunidades de negocio se pueden generar con el subproducto?

\section{Cuestionario: Segmento 2}

¿Cuál es su cargo en la empresa y cuánto tiempo viene desempeñándose en él?

¿Qué entiende por el concepto de gestión de residuos sólidos orgánicos?

¿Usted considera que las agroexportadoras implementan gestión de residuos sólidos orgánicos?, ¿Por qué?

¿Cómo puede contribuir la gestión de residuos sólidos orgánicos en las actividades de agro exportación? 
¿Qué entiendo por el concepto de valorización de residuos sólidos orgánicos?

¿Cuál es la etapa en el proceso de agro exportación donde se genera mayor residuo solido orgánico?

¿Qué método de reutilización de residuos sólidos orgánicos se puede aplicar?

¿Qué subproductos de generan en el cultivo de café que puedan reutilizarse?

¿Qué oportunidades de negocio se pueden generar con el subproducto?

\section{Cuestionario: Segmento 3}

¿Cuál es su cargo en la Institución y cuánto tiempo viene desempeñándose en él?

¿Usted considera que las agroexportadoras implementan gestión de residuos sólidos orgánicos?, ¿Por qué?

¿Cómo puede contribuir con el medioambiente la gestión de residuos sólidos orgánicos en las actividades de agro exportación?

¿Cómo promueve el estado la implementación de residuos sólidos orgánicos?

¿Qué programas fomentan la valorización de residuos sólidos orgánicos en las agroexportadoras?

¿Qué tipos de control o fiscalización aplican?

\section{Cuestionario: Segmento 4}

¿Cuál es su cargo en la empresa y cuánto tiempo viene desempeñándose en él?

¿Usted considera que las agroexportadoras implementan gestión de residuos sólidos orgánicos?, ¿por qué? 
¿Cuáles son las principales limitaciones para implementar la gestión de residuos sólidos orgánicos en las actividades de agro exportación?

¿Cómo puede contribuir la gestión de residuos sólidos orgánicos en las actividades de agro exportación?

¿Qué técnicas de reutilización de residuos orgánicos son las más empleadas por las agroexportadoras?

¿Qué tipo de certificaciones existen que garantizan una buena valorización de los residuos sólidos orgánicos?

\section{Cuestionario: Segmento 5}

¿Cuál es su cargo en la Institución y cuánto tiempo viene desempeñándose en él?

¿Usted considera que las agroexportadoras implementan gestión de residuos sólidos orgánicos?, ¿por qué?

¿Cómo puede contribuir con el medioambiente la gestión de residuos sólidos orgánicos en las actividades de agro exportación?

¿Cómo promueve los gremios la implementación de residuos sólidos orgánicos?

¿Qué técnicas de reutilización de residuos sólidos orgánicos son las más empleadas por las agroexportadoras?

¿Qué programas fomentan la valorización de residuos sólidos orgánicos en las agroexportadoras?

¿Qué subproductos de generan en el cultivo de café?

¿Qué oportunidades de negocio se pueden generar con el subproducto? 